\title{
Analisis Hubungan Manajemen Laba dan Struktur Kepemilikan Terhadap Kinerja Perusahaan di BEI Tahun 2016-2019
}

\author{
Sari Dewi ${ }^{1 *}$, Lisa $^{2}$ \\ Universitas Internasional Batam ${ }^{1,2}$ \\ ${ }^{1)}$ sari@uib.ac.id, ${ }^{2}$ lisa2000969@gmail.com
}

*Penulis Korespondensi

$\begin{array}{ll}\text { Diajukan } & : \text { 10 Juli } 2021 \\ \text { Disetujui } & : 24 \text { Agustus } 2021 \\ \text { Dipublikasi } & : 30 \text { Agustus } 2021\end{array}$

\section{ABSTRACT}

Firm performance includes the activities produced by company management and high firm performance can be said to allow them to plan their work according to their own goals and take risks with full responsibility. This study was conducted to determine the effect of earnings management, the size of the board of directors, and ownership structure (blockholders ownership, institutional ownership, family ownership, and managerial ownership) on the firm's performance. By using sample data listed on the Indonesia Stock Exchange (IDX) from 2016 to 2019. Because there are several previous studies that produce different values on firm performance. Therefore, it is necessary to re-examine this. In this study using the firm's performance with the Tobin's $Q$ model to determine the value of asset management generated by the company. The data used is panel data with secondary data collection techniques to test outliers by SPSS software version 25, then test descriptive statistics, multicollinearity, heteroscedasticityt, $R$ Square, $F$ test and also $t$ test using Eviews software version 10. The results of this study conclude that both accrual-based and real earnings management have a significant positive effect on firm performance, while the size of the board of directors has a significant negative effect on performance. The ownership structure has no significant effect on the firm's performance. The result of insignificant results could be caused by not supporting the agency theory perspective, as well as the lack of company control.

\section{Keywords: Firm Performance, Earnings Management, Ownership Structure, Board Size}

\section{PENDAHULUAN}

Kinerja perusahaan termasuk kegiatan yang dihasilkan oleh manajemen perusahaan, kinerja perusahaan tinggi dapat dikatakan mampu merencanakan kerja sesuai tujuan sendiri dan berani mengambil resiko dengan penuh tanggung jawab. Kinerja perusahaan adalah pencapaian dengan melaksanakan suatu kegiatan atau rencana untuk mencapai suatu tujuan. Dengan menunjukkan tujuan ekonomi yang dapat dicapai perusahaan dalam waktu yang ditentukan (Indarti \& Extaliyus, 2013). Evaluasi kinerja perusahaan dengan menganalisis laporan keuangan merangsang pikiran para pemimpin perusahaan. Dari perspektif proses perusahaan, pengelolaan perkembangan teknologi modern yang pesat merupakan proses yang sangat kompleks.

Pendekatan dari laporan keuangan ialah parameter yang digunakan untuk menilai suatu kinerja perusahaan. Dalam penelitian ini menggunakan metode Tobin's Q yang digunakan untuk mengetahui efisiensi suatu aktivitas perusahaan. James Tobin mengembangkan teori yang dikenal sebagai Tobin's Q yang merupakan perbandingan antara nilai pasar saham perusahaan dan biaya modal. Rasio ini termasuk konsep yang menunjukkan perkiraan pasar keuangan mengenai nilai dari pengembalian perdana yang diinvestasikan. Jika Tobin's Q berada di atas level tertentu, maka investasi aktiva akan menghasilkan pengembalian yang lebih tinggi sedangkan jika Tobin's $Q$ berada di bawah level tertentu, maka investasi aktiva tidak efektif (Zurriah, 2021). Agar dapat 
menguntungkan perusahaan maka manajer harus menunjukkan laporan keuangan perusahaan yang artinya manajemen laba.

Manajemen laba sangat penting bagi perusahaan, sebab dilakukan dengan cara yang relevan dan terpercaya. Personel internal perusahaan menggunakan manajemen laba untuk memanipulasi dan menyusun laporan keuangan (Subadriyah et al., 2020). Memanipulasi laba merupakan tindakan yang melanggar aturan laporan keuangan perusahaan yang dengan sengaja menghasilkan laba yang tidak relevan. Khanh \& Khuong (2018) menyatakan perusahaan meyakini bahwa manajemen laba dianggap sebagai sumber dari berbagai skandal keuangan, yang menimbulkan kekhawatiran publik pada kualitas informasi keuangan.

Manajemen laba dapat dilakukan dengan dua langkah utama yaitu sistem akrual dan aktual (riil). Manajemen laba berdasarkan sistem akrual melibatkan pemilihan opsi akuntansi transaksi tertentu untuk memanipulasi keuntungan yang dilaporkan. Sedangkan manajemen laba basis riil dengan manipulasi keuntungan melalui kegiatan yang aktual. Biasanya manajer lebih sering melakukan manajemen laba dengan sistem riil, karena lebih sulit ditemukan oleh auditor. Masih terdapat banyak perusahaan yang terpengaruh masalah ini demi nilai kinerja. Pada saat yang sama, Khuong et al. (2019) menjelaskan laba berpengertian realitas penting universal yang menentukan status keuangan dan kesehatan semua perusahaan asuransi.

Beberapa kasus yang terjadi di Indonesia yaitu manipulasi laba pada PT Garuda Indonesia Tbk (GIAA) dan PT Tiga Pilar Sejahtera Tbk (AISA). PT GIAA di tahun 2019 telah memanipulasi laba laporan keuangan tahun 2018, yang seharusnya dicatat kerugian tetapi dicatat laba sebesar Rp 11.33 miliar. Atas kejadian tersebut perusahaan tersebut dikenakan denda senilai Rp 100 juta atas dewan direksi yang bertanda tangan pada laporan tersebut (Jannah, 2019). Sedangkan pada tahun 2018 PT AISA melakukan human fraud yang disebabkan karena telah menambah piutang sebanyak 6 perusahaan distributor kedalam laporan keuangan. Akibatnya Bursa membekukan saham AISA di bulan Juli 2018 hingga akhirnya ketika saat skorsing AISA menjual sahamnya, meskipun masih terdapat beberapa investor yang memegang saham tersebut (Situmorang, 2021).

\section{Kinerja Perusahaan}

\section{STUDI LITERATUR}

Kinerja perusahaan merupakan salah satu responsibilitas dari perusahaan kepada pemegang saham yaitu membuat laporan keuangan sehingga laporan tersebut dapat dijadikan sebagai sebuah media komunikasi perusahaan. Dalam manajemen laba berkaitan dengan laporan laba rugi di mana dapat mempengaruhi kinerja perusahaan. Manajemen laba sangat penting untuk membantu perusahaan bertahan, merencanakan strategi masa depan dan meningkatkan kinerja mereka. Ketika dalam membaca laporan keuangan, kebanyakan perusahaan hanya fokus pada pertumbuhan laba bersih tanpa memahami situasi perusahaan secara keseluruhan. Biasanya, seorang investor percaya bahwa peningkatan keuntungan yang luar biasa akan menyebabkan peningkatan tajam pada saham. Sebenarnya perusahaan tetap harus mengkritik peningkatan keuntungan tersebut.

Pada kinerja perusahaan Yordania mengemukakan bahwa manajemen laba berbasis akrual dan riil pada Tobin's Q memiliki hubungan bersignifikan negatif. Peneliti menyatakan bahwa perusahaan yang terlibat pada manajemen akrual dan riil melaporkan penghasilan yang lebih besar di masa depan memiliki kinerja yang lebih sedikit (Dakhlallh et al., 2020). Menurut Mahrani \& Soewarno (2018) pengaruh manajemen laba berbasis akrual bersignifikan negatif terhadap kinerja perusahaan. Sedangkan hasil penelitian Khuong et al. (2019) menunjukkan bahwa manajemen laba berbasis riil menghasilkan hubungan bersignifikan positif pada kinerja perusahaan. Pada waktu yang sama, Adryanti (2019) menemukan manajemen laba basis akrual dan riil berpengaruh signifikan positif pada kinerja perusahaan.

\section{$H_{1}$ : Manajemen Laba Berbasis Riil berpengaruh signifikan positif terhadap Kinerja Perusahaan. \\ $\mathrm{H}_{2}$ : Manajemen Laba Berbasis Akrual berpengaruh signifikan negatif terhadap Kinerja Perusahaan.}


Dewan direksi sangat penting bagi perusahaan dalam melakukan segala tindakan manajemen atas kepemilikan aset perusahaan sesuai dengan batasan yang diatur dalam anggaran dasar perusahaan, termasuk pembatasan perusahaan dan pihak lain dan/ atau pihak lain dan perusahaan. Ukuran dewan direksi ini melindungi kepentingan perusahaan dan konsumen, maka anggota dewan harus bekerja lebih hati-hati dan transparan. Pengaruh dewan direksi pada kinerja perusahaan memiliki hasil signifikan positif, sebab ukuran dewan dapat meningkatkan kinerja perusahaan dengan mengarahkan dan mengontrol proses perusahaan dengan baik (Buachoom, 2018). Waheed \& Malik (2019) mengungkapkan bahwa ukuran dewan direksi terdapat hubungan signifikan positif terhadap kinerja perusahaan. Yang menyatakan direktur perusahaan bisa menyadari peran dan rasa tanggung jawab yang mampu meningkatkan kemampuan dewannya.

\section{$\mathrm{H}_{3}$ : Ukuran Dewan Direksi berpengaruh signifikan positif terhadap Kinerja Perusahaan.}

Ibrahimy \& Ahmad (2020) menjelaskan kepemilikan blockholders ialah kepemilikan yang dapat mempengaruhi kebijakan perusahaan. Kepemilikan tersebut harus memiliki saham sebanyak 5\% atau lebih baik dewan direksi maupun dewan komisaris. Dengan memusatkan kepemilikan dapat mengurangi konflik antara pemegang saham dan manajer. Nilai kepemilikan blockholders utama yang cukup rendah, informasi keuangan terkini masih tersedia di pameran manajemen perusahaan. Hal ini dapat menimbulkan kepercayaan para pemangku kepentingan. Kepemilikan blockholders digunakan sebagai perangkat pemantauan untuk verifikasi peran penting dalam pengambilan keputusan manajemen yang berdasarkan maksimalisasi kepentingan pemegang saham. Ibrahimy \& Ahmad (2020) menyimpulkan bahwa kepemilikan blockholders menghasilkan hubungan signifikan positif dengan kinerja perusahaan. Dengan kata lain, pengawasan manajer dapat meningkatkan kepemilikan pemegang saham serta menunjukkan kemungkinan ada motif yang disembunyi oleh pemegang saham dalam ekonomi Malaysia.

\section{$\mathrm{H}_{4}$ : Kepemilikan Blockholders berpengaruh signifikan positif terhadap Kinerja Perusahaan.}

Kepemilikan institusional merupakan kepemilikan yang mengelola dana atas nama lembaga orang lain/ eksternal perusahaan untuk berinvestasi pada saham. Kepemilikan institusional ini dapat meningkatkan pengawasan sehingga kepemilikan ini penting bagi seorang pengawas manajemen. Jika tingkat saham institusional tinggi maka semakin besar kekuatan suara yang bisa mendapatkan upaya pengawasan yang intensif (Sakawa \& Watanabel, 2020). Investor institusi memiliki insentif yang kuat dalam mengurangi pengontrollan eksploitasi manajer. Sehingga biaya agensi perusahaan berkurang dan kepemilikan institusional dapat memantau manajer hingga meningkatkan nilai kinerja. Hal ini menunjukkan pengaruh kepemilikan institusional bersignifikan positif pada kinerja yang ditemukan oleh Kao et al. (2018).

\section{$\mathrm{H}_{5}$ : Kepemilikan Institusional berpengaruh signifikan positif terhadap Kinerja Perusahaan.}

Perusahaan dipandang sebagai aset yang akan diwariskan kepada generasi penerus milik keluarga. Kepemilikan keluarga memiliki kewajiban untuk mengawasi dan mengontrol pengelola agar lebih efektif dan efisien. Bisnin keluarga didirikan, dipimpin dan dikelola oleh anggota keluarga, meskipun sebagian besar bisnis tersebut saat ini telah dikelola oleh para profesional di luar keluarga. Keluarga sebagai suatu sistem lebih emosional karena terhubung melalui ikatan yang berpengaruh sangat besar dalam berbisnis, di mana seluruh keluarga tetap bersikap setia. Kecuali keluarga itu bersikap konservatif dan meminimalkan perubahan agar tetap utuh. Dalam penelitian Jwailes \& Sulong (2020) dan Hasnan et al. (2019) variabel kepemilikan keluarga memiliki hubungan signifikan positif dengan kinerja perusahaan. Persentase kepemilikan keluarga yang tinggi dan keberadaan pendiri akan meningkatkan kinerja perusahaan serta mempengaruhi investor institusi maupun keluarga.

\section{$\mathrm{H}_{6}$ : Kepemilikan Keluarga berpengaruh signifikan positif terhadap Kinerja Perusahaan.}


Manajer yang memiliki saham di perusahaan maka hal tersebut akan menyelaraskan kepentingan mereka dengan para pemegangnya. Jika manajer tidak memiliki saham di perusahaan, hal ini memungkinkan akan hanya peduli pada kepentingan sendiri (Shan, 2019). Kepemilikan manajerial berpengertian proporsi pemegang saham dari pihak manajemen yang aktif berpartisipasi dalam pengambilan keputusan. Perusahaan memiliki kepemilikan manajemen dalam jumlah besar agar bisa mengawasi aktivitas perusahaan. Kepemilikan saham manajemen yang tinggi dapat mendorong manajemen untuk menjalankan fungsinya dengan benar, dengan dirancang untuk meningkatkan kesejahteraan pemegang saham serta kepentingan sendiri. Menurut Ali et al. (2018), Rasyid \& Linda (2019) dan Talab et al. (2018) kepemilikan manajerial bersignifikan positif dengan kinerja perusahaan. Sehingga dapat mencegahi tingkah laku manajemen yang hanya memikir kepentingan sendiri dan mengatasi konflik agensi.

\section{$\mathrm{H}_{7}$ : Kepemilikan Manajerial berpengaruh signifikan positif terhadap Kinerja Perusahaan.}

\section{METODE}

Penelitian ini bersifat kuantitatif (angka) dengan teknik pengumpulan data sekunder. Penelitian bertujuan untuk menyempurnakan teori penelitian yang ada. Dengan menguji hubungan antara variabel independen dengan dependen yaitu menguji hubungan manajemen laba berbasis riil dan akrual, ukuran dewan direksi, dan struktur kepemilikan yakni: kepemilikan blockholders, kepemilikan institusional, kepemilikan keluarga serta kepemilikan manajerial pada kinerja perusahaan dengan model Tobin's Q. Data sekunder penelitian diambil dari laporan tahunan dan laporan keuangan perusahaan BEI pada tahun 2016 sampai 2019.

Data sampel yang digunakan yaitu sebanyak 729 perusahaan sedangkan sampel yang sesuai kriteria sebanyak 1948 data dari 487 perusahaan dalam jangka waktu 4 tahun (sebelum outlier). Metode yang digunakan yaitu metode regresi data panel untuk menguji pengaruh antar variabel dalam waktu kurun tertentu. Metode analisa menggunakan software SPSS versi 25 untuk menguji outlier dan menggunakan aplikasi Eviews versi 10 untuk menguji statistik deskriptif, pemilihan model yang tepat untuk uji asumsi klasik. Serta melakukan pemilihan model dengan cara meneliti uji Chow, Uji Hausman, Uji $R$ Square, Uji F, dan Uji t (Yusuf, 2017).

\section{Statistik Deskriptif}

\section{HASIL}

Tabel 1. Hasil Statistik Deskriptif

\begin{tabular}{|l|c|c|c|c|c|}
\hline \multirow{2}{*}{ Keterangan } & & & \multicolumn{2}{c|}{ Statistik Deskriptif } & \\
\cline { 2 - 6 } & $\mathbf{N}$ & Minimum & Maksimum & Mean & Std.Deviasi \\
\hline Kinerja Perusahaan & 1938 & -24.6323 & 142.2610 & 1.9984 & 6.1120 \\
\hline Manajemen Laba Akrual & 1938 & -11.5221 & 164.5633 & 0.1345 & 3.7740 \\
\hline Manajemen Laba Riil & 1938 & -162.7511 & 0.0380 & -0.2537 & 3.7055 \\
\hline Ukuran Dewan Direksi & 1938 & 2.0000 & 16.0000 & 4.7482 & 2.0153 \\
\hline Kepemilikan Blockholders & 1938 & 0.0000 & 1.0000 & 0.0487 & 0.1375 \\
\hline Kepemilikan Institusional & 1938 & 0.0000 & 5.5003 & 0.6528 & 0.2618 \\
\hline Kepemilikan Keluarga & 1938 & 0.0000 & 4.0221 & 0.5916 & 0.2630 \\
\hline Kepemilikan Manajerial & 1938 & 0.0000 & 0.9970 & 0.0436 & 0.1241 \\
\hline
\end{tabular}

Dari tabel diatas, dapat disimpulkan bahwa jumlah data sampel yang sesuai kriteria sebanyak 1948 data dari tahun 2016 hingga 2019. Selain itu terdapat data outlier sebanyak 10 data sehingga data sampel yang diobservasi sejumlah 1938 data. Hasil tabel tersebut menyatakan ratarata kinerja perusahaan senilai 1.9984 yang berarti aset perusahaan telah dibiayai utang. Dari hasil output nilai maksimum manajemen laba akrual terbanyak dibandingkan dengan variabel lainnya sebesar 164.5633, sedangkan rata-rata dari manajemen laba riil sebesar -0.2537 dikarenakan terdapat perusahaan yang menggunakan income minimization ketika profitabilitas tinggi. 
Nilai minimum dari ukuran dewan direksi sebanyak 2 yang artinya dalam perusahaan hanya terdapat 2 dewan direksi sedangkan nilai maksimum ukuran dewan direksi sebanyak 16 berarti perusahaan memiliki 16 dewan direksi sehingga dalam mengambil keputusan membutuhan banyak waktu akan tetapi dengan begitu perusahaan dapat membuat network antar pihak dari luar perusahaan sehingga dapat meningkatkan kinerja. Nilai minimum struktur kepemilikan (kepemilikan blockholders, kepemilikan institusional, kepemilikan keluarga dan kepemilikan manajerial) menghasilkan hasil yang sama yakni senilai 0 . Nilai mean dari kepemilikan keluarga sebesar 0.5916 dapat disimpulkan variasi yang cukup tinggi maka mampu meningkatkan fungsi pengawasan. Nilai maksimum kepemilikan manajerial sebesar 0.9970 dari jumlah saham dewan direksi dan dewan komisaris dalam perusahaan.

\section{Multikolinearitas}

Tabel 2. Hasil Multikolinearitas

\begin{tabular}{|c|c|c|c|c|c|c|c|}
\hline Variabel & $\begin{array}{c}\text { Manajemen } \\
\text { Laba } \\
\text { Akrual }\end{array}$ & $\begin{array}{l}\text { Manajemen } \\
\text { Laba Riil }\end{array}$ & $\begin{array}{l}\text { Ukuran } \\
\text { Dewan } \\
\text { Direksi }\end{array}$ & $\begin{array}{l}\text { Kepemilikan } \\
\text { Blockholders }\end{array}$ & $\begin{array}{l}\text { Kepemilikan } \\
\text { Institusional }\end{array}$ & $\begin{array}{c}\text { Kepemilikan } \\
\text { Keluarga }\end{array}$ & $\begin{array}{c}\text { Kepemilikan } \\
\text { Manajerial }\end{array}$ \\
\hline $\begin{array}{l}\text { Manajemen } \\
\text { Laba Akrual }\end{array}$ & 1.0000 & -0.9849 & 0.0106 & -0.0076 & 0.0221 & 0.0316 & -0.0045 \\
\hline $\begin{array}{l}\text { Manajemen } \\
\text { Laba Riil }\end{array}$ & 1.0000 & 1.0000 & $\begin{array}{c}- \\
0.0005\end{array}$ & 0.0104 & -0.0308 & -0.0425 & 0.0099 \\
\hline $\begin{array}{l}\text { Ukuran } \\
\text { Dewan } \\
\text { Direksi }\end{array}$ & 0.0106 & -0.0005 & 1.0000 & -0.0761 & 0.0786 & 0.0677 & -0.0591 \\
\hline $\begin{array}{l}\text { Kepemilikan } \\
\text { Blockholders }\end{array}$ & -0.0076 & 0.0104 & $\begin{array}{c}- \\
0.0761\end{array}$ & 1.0000 & -0.4232 & -0.0433 & 0.6745 \\
\hline $\begin{array}{l}\text { Kepemilikan } \\
\text { Institusional }\end{array}$ & 0.0221 & -0.0308 & 0.0786 & -0.4232 & 1.0000 & 0.5614 & -0.4025 \\
\hline $\begin{array}{l}\text { Kepemilikan } \\
\text { Keluarga }\end{array}$ & 0.0316 & -0.0425 & 0.0677 & -0.0433 & 0.5614 & 1.0000 & -0.0265 \\
\hline $\begin{array}{l}\text { Kepemilikan } \\
\text { Manajerial }\end{array}$ & -0.0045 & 0.0099 & $\begin{array}{c}- \\
0.0591 \\
\end{array}$ & 0.6745 & -0.4025 & -0.0265 & 1.0000 \\
\hline
\end{tabular}

Kriteria pengujian multikolinearitas ialah menguji nilai korelasi yang dihasilkan antar semua independen. Dari hasil output dapat dinyatakan penelitian ini tidak memiliki masalah multikolinearitas sebab hasil dari semua independen lebih kecil dari 0.8 sehingga nilai standar error untuk uji tersebut kecil.

\section{Heteroskedastisitas}

Tabel 3. Hasil Heteroskedastisitas

\begin{tabular}{|l|l|c|}
\hline Variabel Dependen & $\begin{array}{l}\text { Prob. } \\
\text { Chi.Square(7) }\end{array}$ & \multicolumn{1}{c|}{ Kesimpulan } \\
\hline Kinerja Perusahaan & 0.9381 & Tidak terjadi masalah Heteroskedastisitas \\
\hline
\end{tabular}

Untuk uji berikut ini dengan menggunakan tipe white untuk mengetahui data penelitian akan terjadi atau tidaknya masalah heteroskedastisitas. Hasil uji diatas menunjukkan sebesar 0.9381 yang dapat dikatakan tidak terjadi masalah heteroskedastisitas karena nilai probabilitas lebih besar dari 0.05 (menerima $\mathrm{H}_{0}$ ). 
Owner: Riset \& Jurnal Akuntansi

e-ISSN : 2548-9224 |p-ISSN : 2548-7507

Volume 5 Nomor 2, Agustus 2021

\section{Pemilihan Model Regresi Data Panel}

Uji Chow

Tabel 4. Hasil Uji Chow

\begin{tabular}{|c|c|c|c|}
\hline Effects Test & Statistic & Prob. & Kesimpulan \\
\hline Cross-section $F$ & 7.5622 & 0.0000 & - \\
\hline Cross-section Chi-square & 2448.8976 & 0.0000 & Fixed Effect Model \\
\hline
\end{tabular}

Hasil di atas dapat disimpulkan bahwa nilai probabilitas dari cross-section Chi-square adalah 0,0000 di mana hasil tersebut tidak mencapai $\geq 0.05$ sehingga dapat dikatakan model yang paling tepat ialah fixed effect model (FEM) dengan ketentuan hasil probabilitas $<0.05$.

\section{Uji Hausman}

Tabel 5. Hasil Uji Hausman

\begin{tabular}{|c|c|c|c|}
\hline Test Summary & Chi-Sq. Statistic & Prob. & Kesimpulan \\
\hline Cross-section random & 319.48932 & 0.0000 & Fixed Effect Model \\
\hline
\end{tabular}

Hasil output ini menyimpulkan nilai probabilitas dari cross-section random adalah 0,0000 yang artinya kecil dari 0.05 maka model yang paling cocok untuk uji regresi data panel yaitu model FEM.

\section{Pengujian Hipotesis \\ Uji R Square}

Tabel 6. Hasil Uji R Square

\begin{tabular}{|l|l|r|}
\hline Variabel Dependen & Uji $\boldsymbol{R}$ Square & Sig \\
\hline Kinerja Perusahaan & Adjusted R-Squared & 0.65507 \\
\hline
\end{tabular}

Dari tabel diatas, hasil uji $R$ squared dengan signifikan sebesar 0.65507 , dengan kata lain sebesar $65 \%$ semua variabel independen secara simultan/ bersamaan mempengaruhi variabel dependen. Kemudian sisa dari persentase tersebut yang menyimpulkan bahwa ada variabel lain tanpa diteliti mempengaruhi variabel dependen (kinerja perusahaan).

\section{Uji F}

Tabel 7. Hasil Uji F

\begin{tabular}{|l|l|r|}
\hline Variabel Dependen & Uji F & Sig \\
\hline Kinerja Perusahaan & Prob(F-statistic) & 0.00000 \\
\hline
\end{tabular}

Hasil output uji ini menyatakan hasil probabilitasnya senilai 0,00000 dengan model FEM. Yang data disimpulkan untuk variabel independen (manajemen laba akrual, manajemen laba aktual, ukuran dewan direksi, kepemilikan blockholders, kepemilikan institusional, kepemilikan keluarga dan kepemilikan manajerial) pada penelitian ini berpengaruh signifikan pada variabel dependen (kinerja perusahaan) dengan sesuai standar $<$ dari 0.05 .

\section{Uji t}

Tabel 8. Hasil Uji t

\begin{tabular}{|l|c|c|c|c|}
\hline \multicolumn{1}{|c|}{ Variabel } & Coefficient & Prob. & Keterangan & Hipotesis \\
\hline Manajemen Laba Akrual & 1.649033 & 0.0000 & Signifikan Positif & 1 \\
\hline Manajemen Laba Riil & 1.83608 & 0.0000 & Signifikan Positif & 2 \\
\hline
\end{tabular}




\begin{tabular}{|l|c|c|c|c|}
\hline Ukuran Dewan Direksi & -0.568244 & 0.0001 & Signifikan Negatif & 3 \\
\hline Kepemilikan Blockholders & -0.325373 & 0.8454 & Tidak Signifikan & 4 \\
\hline Kepemilikan Institusional & -0.642832 & 0.3575 & Tidak Signifikan & 5 \\
\hline Kepemilikan Keluarga & 0.128559 & 0.8759 & Tidak Signifikan & 6 \\
\hline Kepemilikan Manajerial & 0.079134 & 0.9726 & Tidak Signifikan & 7 \\
\hline
\end{tabular}

Dari hasil uji $\mathrm{t}$ disimpulkan bahwa variabel independen manajemen laba akrual berpengaruh signifikan positif pada kinerja perusahaan di mana dapat diketahui hasil probabilitasnya sebesar 0.000 dan nilai koefisien 1.6490 dengan kata lain hipotesis ini terbukti.

Hipotesis ke-2 disimpulkan bahwa variabel independen manajemen laba aktual berhubungan signifikan positif dengan kinerja perusahaan dengan hasil probabilitasnya sebesar 0.0000 dan nilai koefisien 1.8360 maka dari itu dapat dikatakan hipotesis tersebut terbukti/ dapat diterima.

Hipotesis ke-3, variabel ukuran dewan direksi berpengaruh secara negatif pada kinerja di mana dilihat dari hasil probabilitasnya sebesar 0,0001 dan nilai koefisien -0.5682 serta dapat dikatakan hipotesis ini terbukti. Dengan banyaknya anggota direksi maka akan membuat network bersama pihak dari luar sehingga kinerja perusahaan akan semakin baik (Waheed \& Malik, 2019).

Hasil uji thipotesis ke-4 disimpulkan bahwa kepemilikan blockholders tidak berpengaruh signifikan pada kinerja perusahaan di mana dapat diketahui hasil probabilitasnya sebesar 0,8454 dengan nilai koefisien sebesar -0.3253 maka dapat dikatakan hipotesisnya tidak terbukti. Sehingga hipotesis yang diajukan tersebut tidak mendapat dukungan dari penelitian ini.

Kepemilikan institusional tidak berpengaruh signifikan pada kinerja yang dapat diketahui dari hasil probabilitasnya sebesar 0,3575 dan nilai koefisien -0.6428 serta dapat dikatakan hipotesisnya tidak terbukti/ditolak. Sehingga hipotesis yang diajukan tersebut tidak mendapat dukungan dari penelitian ini.

Hipotesis ke-6 dapat dikaji variabel independen kepemilikan keluarga tidak berhubungan signifikan pada kinerja perusahaan yang telah diketahui pada tabel diatas hasil probabilitasnya sebesar 0.8759 dan nilai koefisien 0.1285 maka dapat dikatakan hipotesisnya tidak terbukti/ ditolak.

Dilihat dari hasil probabilitas sebesar 0,9224 dan nilai koefisien 0,473564 maka hasil uji dari hipotesis ke-7 dapat dinyatakan bahwa variabel independen kepemilikan manajerial tidak berpengaruh signifikan pada kinerja perusahaan sehingga dapat dikatakan hipotesis ini tidak terbukti/ditolak.

\section{PEMBAHASAN}

\section{Pengaruh Manajemen Laba dengan Kinerja Perusahaan}

Menurut Adryanti (2019), Oktavani \& Devie (2017), dan Santoso \& Widyaswati (2017) menunjukkan praktik manajemen laba tidak akan mempengaruhi kinerjanya, sebab nilai kinerja yang baik mampu mengurangi praktik manajemen laba. Maka hipotesis ini mendapatkan dukungan dari penelitian/telah diterima.

\section{Pengaruh Ukuran Dewan Direksi dengan Kinerja Perusahaan}

Hasil penelitian ini terdapat kesamaan dengan penelitian Ding et al. (2018), Khuong et al. (2019), dan Surifah (2017) yang mengatakan bahwa dengan hasil signifikan positif maka dapat dibuktikan semakin tinggi manajemen laba riil semakin baik praktik bisnis perusahaan. Manajer harus berusaha mencari cara lain agar kinerja perusahaan tetap meningkat.

\section{Pengaruh Kepemilikan Blockholders dengan Kinerja Perusahaan}

Hasil penelitian diatas menyimpulkan variabel indenpenden ini tidak berpengaruh dengan dependen. Akibat dari hasil tersebut tidak dapat meningkatkan nilai kinerja, mengendali, mengawas perusahaan dengan baik (Horobet et al., 2019). 


\section{Pengaruh Kepemilikan Institusional dengan Kinerja Perusahaan}

Hasil tersebut menunjukkan hasil yang setara dengan penelitian Hamza (2018) dan Salehi et al. (2020) menyatakan bahwa monitor pemegang saham institusional harus dikurangi untuk mengurangi konflik kelembagaan. Dengan adanya kegiatan monitor ini maka akan mengarahkan manajemen untuk bertindak demi kepentingan pemegang saham.

\section{Pengaruh Kepemilikan Keluarga dengan Kinerja Perusahaan}

Dari hasil penelitian dinyatakan kepemilikan keluarga tidak berpengaruh signifikan pada kinerja. Hasil penelitian ini tidak mendukung perspektif teori keagenan yang mempengaruhi kepemilikan keluarga pada kinerja perusahan (1-Saidi \& Al-Shammari, 2015).

\section{Pengaruh Kepemilikan Manajerial dengan Kinerja Perusahaan}

Hasil penelitian menyimpulkan kepemilikan manajerial tidak bersignifikan terhadap kinerja perusahaan sehingga tidak sejalan dengan penelitian Shan (2019) yang menyatakan dengan bertambahnya saham dari manajer maka perusahaan tersebut mampu menurunkan kinerja keuangannya.

\section{KESIMPULAN}

Berdasarkan pengujian mengenai hubungan variabel kinerja perusahaan dengan model Tobin's $Q$ dan independennya terdiri dari manajemen laba akrual, manajemen laba riil, ukuran dewan direksi kepemilikan blockholders, kepemilikan institusional, kepemilikan keluarga dan kepemilikan manajerial. Dari hasil pengujian dapat disimpulkan bahwa manajemen laba akrual dan manajemen laba riil bersignifikan positif pada kinerja perusahaan kemudian untuk variabel ukuran dewan direksi berpengaruh signifikan negatif pada dependen kinerja perusahaan. Sedangkan variabel kepemilikan blockholders, kepemilikan institusional, kepemilikan keluarga dan kepemilikan manajerial tidak berpengaruh signifikan pada kinerja dalam topik penelitian ini.

\section{REFERENSI}

Adryanti, A. F. (2019). Pengaruh pilihan metode manajemen laba akrual dan riil terhadap kinerja Keuangan perusahaan sektor manufaktur. Jurnal Studi Akuntansi Dan Keuangan, 2(1), 4762. https://doi.org/10.29303/akurasi.v2i1.14

Al-Saidi, M., \& Al-Shammari, B. (2015). Ownership concentration, ownership composition and the performance of the Kuwaiti listed non-financial firms. International Journal of Commerce and Management, 25(1), 108-132. https://doi.org/10.1108/IJCOMA-07-2013-0065

Ali, A., Qiang, F., \& Ashraf, S. (2018). Regional dynamics of ownership structure and their impact on firm performance and firm valuation: A case of Chinese listed companies. Review of International Business and Strategy, 28(1), 128-146. https://doi.org/10.1108/RIBS-02-20170017

Buachoom, W. (2018). How do board structures of Thai firms influence on different quantile levels of firm performance? Advances in Pacific Basin Business, Economics and Finance, 6, 157189. https://doi.org/10.1108/s2514-465020180000006004

Dakhlallh, M. M., Rashid, N., Abdullah, W. A. W., Qawqzeh, H. K., \& Dakhlallh, A. M. (2020). Accrual-based earnings management, real earnings management and firm performance: evidence from public shareholders listed firms on Jordanian's stock market. Journal of Advanced Research in Dynamical and Control Systems, 12(1), 16-27. https://doi.org/10.5373/JARDCS/V12I1/20201004

Ding, R., Li, J., \& Wu, Z. (2018). Government affiliation, real earnings management, and firm performance: The case of privately held firms. Journal of Business Research, 83, 138-150. https://doi.org/10.1016/j.jbusres.2017.10.011

Hamza, S. M., \& Suman, S. S. (2018). The impact of ownership structure on firm performance: A study on bombay stock exchange in India. International Journal of Accounting \& Business 
Management, 6(1), 21-38. https://doi.org/10.24924/ijabm/2018.04/v6.iss1.21.38

Hasnan, S., Kamaruzaman, I. S., Sanusi, Z. M., \& Ali, M. M. (2019). Political connections, family ownership and firms' performance in Malaysia. International Journal of Innovation, Creativity and Change, 7(6), 114-136.

Horobet, A., Belascu, L., Curea, S. C., \& Pentescu, A. (2019). Ownership concentration and performance recovery patterns in the European Union. Sustainability (Switzerland), 11(4). https://doi.org/10.3390/su11040953

Ibrahimy, A. I., \& Ahmad, R. (2020). Blockholder ownership as governance mechanism on firm performance: Evidence from Malaysia. International Journal of Business Administration, 11(1), 27. https://doi.org/10.5430/ijba.v11n1p27

Indarti, M. K., \& Extaliyus, L. (2013). Pengaruh corporate governance preception index(CGPI), struktur kepemilikan, dan ukuran perusahaan terhadap kinerja keuangan. Jurnal Bisnis Dan Ekonomi (JBE), 20(2), 171-183.

Jannah, S. M. (2019). BEI meminta penjelasan garuda soal laporan keuangan. https://tirto.id/beiminta-penjelasan-garuda-soal-laporan-keuangan-mencurigakan-dm9E

Jwailes, A. R., Sulong, Z., \& Ahmad, N. (2020). The ownership structure influence on firm performance in Jordan. International Journal of Advance Science and Technology, 29(10S), 1099-1109.

Kao, M. F., Hodgkinson, L., \& Jaafar, A. (2018). Ownership structure, board of directors and firm performance: evidence from Taiwan. Corporate Governance (Bingley), 19(1), 189-216. https://doi.org/10.1108/CG-04-2018-0144

Khanh, H. T. M., \& Khuong, V. K. (2018). Audit quality, firm characteristics and real earnings management: The case of listed Vietnamese firms. International Journal of Economics and Financial Issues, 8(4), 243-249. http:www.econjournals.com

Khuong, N. V., Ha, N. T. T., \& Thu, P. A. (2019). The relationship between real earnings management and firm performance: the case of energy firms in Vietnam. International Journal of Energy Economics and Policy, 9(2), 307-314. https://doi.org/10.32479/ijeep.7469

Mahrani, M., \& Soewarno, N. (2018). The effect of good corporate governance mechanism and corporate social responsibility on financial performance with earnings management as mediating variable. Asian Journal of Accounting Research, 3(1), 41-60. https://doi.org/10.1108/ajar-06-2018-0008

Oktavani, S., \& Devie. (2017). Pengaruh earnings management terhadap firm value melalui financial performance sebagai variabel intervening pada perusahaan yang terdaftar di LQ 45 value. Business Accounting Review, 5(2), 25-34.

Rasyid, R., \& Linda, M. R. (2019). Ownership structure, capital structure and firm performance: A case in Indonesia. Advances in Economic, Business and Management Research, 97(Piceeba), 766-776. https://doi.org/10.2991/piceeba-19.2019.84

Sakawa, H., \& Watanabel, N. (2020). Institutional ownership and firm performance under stakeholder-oriented corporate governance. Sustainability (Switzerland), 12(3). https://doi.org/10.3390/su12031021

Salehi, M., Mahmoudabadi, M., Adibian, M. S., \& Ranjbar, H. R. (2020). The potential impact of managerial entrenchment on firms' corporate social responsibility activities and financial performance: evidence from Iran. International Journal of Productivity and Performance Management. https://doi.org/10.1108/IJPPM-06-2019-0259

Santoso, A., \& Widyaswati, R. (2017). The Effect of earnings management on company's performance with audit quality and company's size as moderating variabel. Telaah Bsnis, 18(2), 97-106. http://journal.stimykpn.ac.id/index.php/tb

Shan, Y. G. (2019). Managerial ownership, board independence and firm performance. Accounting Research Journal, 32(2), 203-220. https://doi.org/10.1108/ARJ-09-2017-0149

Situmorang, R. T. (2021). Kasus laporan keuangan AISA, pengamat: Human fraud. https://kabar24.bisnis.com/read/20210222/16/1359397/komentari-kasus-laporan-keuanganaisa-pengamat-itu-human-fraud

Subadriyah, S., Sa'diyah, M., \& Murniati. (2020). Praktik manajemen laba: Sebuah kajian studi hermeneutika. Jurnal Ekonomi Dan Bisnis, 23(2), 225-242. 
https://doi.org/10.24914/jeb.v23i2.2129

Surifah, S. (2017). The role of corporate governance in the effect earnings management has on firm value. Journal of Indonesian Economy and Business, 32(1), 51-69.

Talab, H. R., Manaf, K. B. A., \& Malak, S. S. D. A. (2018). Ownership structure, external audit and firm performance in Iraq. Social Science and Humanities Journal, 2(2), 343-353.

Waheed, A., \& Malik, Q. A. (2019). Board characteristics, ownership concentration and firms' performance: A contingent theoretical based approach. South Asian Journal of Business Studies, 8(2), 146-165. https://doi.org/10.1108/SAJBS-03-2018-0031

Yusuf, M. (2017). Pengaruh kompetensi, tekanan ketatan dan kompleksitas terhadap audit judgment. Jurnal Akuntansi Dan Manajemen, 13(01), 167-185.

Zurriah, R. (2021). Pengaruh free cash flow terhadap nilai perusahaan. Jurnal Riset Akuntansi Dan Bisnis, 2l(1), 101-106. 